\title{
Zero-a-Seis
}

\section{DEPOIMENTO SOBRE O FECHAMENTO DAS CRECHES NA ITÁLIA: COMO RESISTIR À INCERTEZA EM TEMPOS DE PANDEMIA? ${ }^{1}$}

Testimonianza sulla chiusura dei nidi in Italia: come resistere all'incertezza in tempi di pandemia?

Testimony on the closure of ECEC in Italy: How to resist uncertainty in times of pandemic?

Susanna MANTOVANI

Professora emérita de Pedagogia geral e social Università degli studi Milano Bicocca

Milano, Italia

susanna.mantovani@unimib.it

https://orcid.org/0000-0002-2608-7795 0
Tradução: Daniela Aparecida VIEIRA Doutora em Letras pela Universidade de São Paulo

Professora de português e de italiano Centro Integrado de Educação de Jovens e Adultos (CIEJA) Perus I São Paulo, Brasil daniela.apvieira@yahoo.com.br http://orcid.org/0000-0002-1197-7429

A lista completa com informações dos autores está no final do artigo

As crianças, sobretudo as crianças menores, podem resistir ao que aconteceu e está acontecendo no mundo se os seus pais e as suas mães resistem e não ficam desorganizados(as) e abatido(as).

As crianças pequenas são fortíssimas, podem aprender tudo, podem resistir a tudo desde que tenham o necessário para viver e relações calorosas, sólidas, significativas. Para elas, estar perto de suas mães e de seus pais é a coisa mais importante; melhor se há, também, outros irmãos e irmãs.

As crianças também são, porém, os "sensores" do que acontece ao redor delas e, portanto, nos advertem quanto à incerteza, ao medo, e nós, hoje, não podemos saber se isso influirá em seu desenvolvimento futuro. Temos de ter esperança, porque é na resistência e na força das crianças que nós também podemos encontrar a

\footnotetext{
1 Revisão técnica: Ana Lúcia Goulart de Faria. Doutora em Educação e Pós-doutora pela Università di Milano Bicocca: E-mail: cripeq@unicamp.br (http://orcid.org/0000-0002-1886-3790).
} 
esperança e a razão para não nos abatermos e para conseguirmos olhar para o futuro através delas.

O que aconteceu - refiro-me à Itália - limitou as experiências dos meninos e das meninas: a possibilidade de ficar ao ar livre, por exemplo, sobretudo na Lombardia, em Milão, em Bergamo, onde a pandemia começou e explodiu e onde, já no inverno, frequentemente, as crianças ficam fechadas em casa; o encontro com outras crianças da mesma idade ou de idades próximas (a Itália é o país com a taxa de natalidade mais baixa do mundo, juntamente com o Japão): para muitíssimos/as meninos e meninas italianos/as, é possível encontrar outras crianças fora de casa somente nas creches, nas pré-escolas ou nos parques públicos. Todos foram fechados.

Na Itália, 94\% das crianças vão à escola a partir dos 3 anos, 23\% vão à creche (mas esse é um percentual médio, que vai dos 55\% em algumas cidades do Norte aos $2 \%$ em algumas do Sul). Todas as crianças que vivem na Itália podem ter um pediatra de família gratuito e também têm o direito de receberem cuidados e serem vacinadas gratuitamente em um hospital ou nos Centros de Saúde do território sem que sejam solicitadas informações às suas famílias. Essa é uma grande proteção e um direito importante, porém muitos - sobretudo nas grandes cidades - vivem em habitações muito pequenas e com muitas pessoas. Em geral, podemos dizer que, na Itália, a saúde das crianças pode ser considerada suficientemente protegida; já a sua vida social, nem tanto.

O que relato a seguir é, principalmente, uma crônica, um testemunho. Não se trata de pensamentos bem delineados de uma estudiosa, de uma pesquisadora. Estou muito envolvida para poder raciocinar cientificamente e sob essa perspectiva. Mas acredito que o pensamento sobre as crianças tenha sentido apenas se conseguirmos pensar em cada menino ou menina concreto ou concreta que encontramos. Não é o momento de pensar na infância, "na infância" em teoria; mesmo diante dos compromissos e da pressão política, devemos ter, em nossa mente, em nossas ações e em nossas palavras, as crianças que têm um nome - Veronica, Lorenzo, Gisel, Kuba, Giulia... - devemos pensar em suas emoções, em suas vidas cotidianas, em suas casas, em seus pais e em suas mães. Somente falando de cada uma delas, poderemos ser melhor escutadas.

Nesses meses, estive muito ocupada com relação às crianças. Com o Ministério na Comissão 0 a 6 e com o Gruppo Nazionale Nidi Infanzia, colaborei com o Instituto Superior de Saúde para redigir um documento cujo foco eram as crianças mais 
vulneráveis, com a nossa Creche e com a nossa Pré-escola na Bicocca. Por fim, colaborei com uma pesquisa, em andamento, sobre as opiniões dos pais e mães das crianças entre 12 meses e 5 anos e entre 6 e 10 anos de idade, por meio de questionário que examina a colaboração com a rede de pediatras da família. Mas estou dentro das coisas e ainda não consigo olhá-las à distância, não sou capaz e temo que ninguém seja capaz de compreender, em profundidade, o significado do que está acontecendo, nem imaginar que consequências isso terá no futuro.

Resistir à incerteza apoiando-nos em nossa experiência, mas abertas ao novo e a mudanças inevitáveis: isso é o que procuro, procuramos fazer com tantas colegas que trabalham nessa área, tornando visíveis os meninos e as meninas e tornando audíveis as suas vozes e as vozes dos seus pais e das suas mães.

Os primeiros dados da nossa pesquisa, realizada, por enquanto, na Lombardia, com uma boa distribuição entre todas as províncias e entre áreas metropolitanas e áreas rurais e montanhosas (até hoje, temos 2700 respostas aos questionários, mas a coleta de dados ainda está em andamento). As dificuldades demonstradas pelas crianças (e pelos pais e mães) são inversamente proporcionais à idade; as crianças de 0 a 5 anos sofreram menos dos que as crianças maiores e do que as suas famílias, e as crianças de 0 a 3 anos sofreram menos do que aquelas entre 3 e 6 anos. A consciência crescente provoca maiores alterações nos comportamentos (raiva, birra, dificuldade de dormir, dificuldade com o distanciamento dos pais). A exposição à TV e às tecnologias foi maciça, sobretudo por parte das crianças maiores, e seus pais/suas mães declaram sentir-se culpados. As dificuldades são e serão, em particular, das mães que perderam ou temem perder o trabalho, ou que trabalharam exaustivamente de casa se podiam utilizar o trabalho remoto e que, agora, pensam no futuro que se mostra incerto e difícil. Em 30\% das respostas, descobrimos que ambos, pai e mãe, que fazem trabalho remoto de casa estavam com dificuldade de gerir, ao mesmo tempo, uma ou mais crianças: é difícil ter, por perto, a mãe ou o pai e não ter a sua atenção.

Alguns distúrbios do sono, despertamentos repentinos, algumas regressões mais marcadas, novamente, na faixa etária dos 3 aos 6 anos em comparação com a de 0 a 3 anos, um grande cansaço dos pais e das mães. Certo número de pais e mães diz que as relações, nesses meses, melhoraram, porém, a preocupação com o futuro os/as aflige. À medida que as crianças se tornam maiores, as preocupações aumentam, sobretudo a preocupação com o excesso de exposição aos instrumentos digitais e à internet. 
Certamente, as crianças que são filhas de pais e mães imigrantes e as crianças com necessidades especiais tiveram, têm e terão mais dificuldade, porque perderam a sua única possibilidade de socialização ampla - a creche, a pré-escola e a escola - e não puderam ter a oportunidade de aprender ou de continuar aprendendo a língua italiana: a creche, a pré-escola e a escola são muito importantes para a aprendizagem linguística, e muitas pesquisas nos mostram que as crianças que falam língua materna diferente da língua italiana e frequentaram regularmente a creche e a pré-escola adquirem uma competência linguística muito satisfatória e preciosa e têm menos dificuldade na escola. Nessa idade, em que a linguagem se desenvolve, mais de 6 meses em que não se fala a segunda língua (as creches e as pré-escolas, como todas as outras escolas, estão fechadas na Itália desde 24 de fevereiro e serão reabertas em 7 de setembro) é muito tempo e incidem na aquisição linguística. Educadoras e professoras deverão se dar conta dessa longa pausa e criar situações naturais e agradáveis, nas quais as crianças possam recuperá-lo.

Os nossos dados (de um segundo questionário, o qual foi distribuído pelos pediatras da família) confirmam que quem sofreu mais foram as crianças a partir de 6 anos e, em especial, as crianças das escolas (de 6 a 11 anos), e seus pais e suas mães.

Depois de algumas semanas sem atividades, todas as escolas deram início a atividades a distância, mas, em geral, não foram satisfatórias. As propostas de conteúdos e as "aulas" eram precárias e, frequentemente, medíocres, mas ocupavam muitas horas, as trocas com a professora e com os/as companheiros/as eram escassas, as tarefas eram excessivas (os pais e as mães afirmam isso).

Isso evidenciou a preparação insuficiente da escola italiana para a DAD (didática a distância) e evidenciou a desigualdade digital: muitas famílias tinham apenas um ou dois celulares e não podiam se conectar, ou colocar à disposição das crianças vários outros dispositivos. Na idade em que estão na escola, as crianças não conseguem fazer sozinhas as atividades, e muitos pais/muitas mães tiveram de comprar equipamentos digitais, scanner etc. Algumas associações e, em parte, mesmo que um pouco tarde, o Ministério, distribuíram tablets e outros equipamentos, mas, certamente, de modo insuficiente; nem todos os pais e as mães eram capazes de ajudar as crianças, ou não tinham tempo para fazê-lo. Tudo isso acentuou a desigualdade entre famílias abastadas e famílias desfavorecidas. Mesmo no caso de famílias em que os pais e as mães trabalham à distância, de casa, o compartilhamento do espaço, os tempos e a instrumentação digital criaram grandes 
dificuldades. Mas, sobretudo na DAD, faltaram o encontro, a relação com as professoras e a interação, o contato direto, pelo menos, à distância. Muitas aulas sem ver as professoras, muitas tarefas, poucos contatos.

A pré-escola começou mais tarde, mas trabalhou muito melhor. As educadoras agiram de modo espontâneo, pensando nas crianças e encontraram formas de estabelecer contatos, mesmo antes que a instituição escolar se movesse. A Comissão Ministerial - 0 a 6 anos - publicou, no início de abril, um documento propondo também com base em experiências já existentes - as LEAD (Legami Educativi $A$ Distanza, Vínculos Educativos a Distância), que destaca os encontros, a comunicação entre professores/as e pais e mães, a escuta dos pais e das mães em grupo e individualmente, recomendando delicadeza ao entrar na vida familiar e propondo um novo "pacto de corresponsabilidade" com os pais e as mães. A indicação era propor materiais, possibilitar liberdade nos feedbacks, promover encontros com e entre as crianças, com e entre os pais e as mães.

A experiência confirmou que o documento foi bem-recebido por professoras e educadoras ("somos reconhecidas", muitas escreveram), criou redes e inspirou experiências novas. Em algumas das Regiões, as creches também estabeleceram contato com as crianças e as famílias.

Nós, da pré-escola e da creche Bambini Bicocca, também organizamos pequenas web-conferences com as crianças: no primeiro encontro, uma criança da Creche abraçou o celular da mãe, quando reviu, pela primeira vez, na tela do celular, a sua educadora. Em nível nacional, porém, não sabemos, até hoje, quantas crianças estiveram envolvidas, mas, com certeza, o mundo profissional da infância teve uma atuação melhor do que o resto da escola, com mais liberdade, mais criatividade, usando, também, o próprio telefone, e não só o computador, com mais atenção às necessidades emotivas das crianças e dos pais e das mães. É um exemplo para o futuro próximo, se ainda tiverem de ser reduzidos os contatos presenciais e mantidos os contatos a distância para as entrevistas, para os encontros com os pais e mães.

É o sinal - quero ser otimista - de uma "cultura da infância" mais atenta ao bem-estar das crianças e das famílias.

Foram propostos e disponibilizados sites e materiais - entre outros, Reggio Children e Bambini Bicocca, e as visualizações foram muito numerosas.

A partir do mês de abril, após mais de um mês de lockdown, levantaram-se muitas vozes que pediam para "liberar as crianças" que não podiam sair ao ar livre e encontrar outras crianças. Criou-se um grupo, Alleanza Civica, promovido, entre 
outros, por Chiara Saraceno, a socióloga que, desde o final dos anos 1970, empenhou-se para o desenvolvimento das instituições voltadas para a infância. Infelizmente, houve incertezas, dúvidas, contraposições, um pouco de fragmentação entre as vozes e as iniciativas: esse tempo tão difícil não conseguiu cessar os protagonismos de muitos e criar uma rede compacta. As pressões, porém, levaram a encontrar recursos novos (embora ainda insuficientes) para sustentar e ampliar, pelo menos em parte, o sistema 0-6 no futuro. O Departamento da Família empenhou-se para reabrir, em junho, os Centros recreativos de verão para as crianças, mesmo as pequenas e pequenininhas, embora com muitas restrições. Isso fez aumentar os custos para os/as gestores/as, para as prefeituras e para muitas famílias: grupos com, no máximo, 5 crianças de até 5 anos de idade; grupos com, no máximo, 7, de 6 a 11 anos; protocolos de saúde e de segurança muito rígidos.

Para alguns de nós, inclusive, para mim (na nossa pré-escola, que recebeu crianças entre 2 e 6 anos), foi um primeiro desafio para testar como será a retomada em setembro: até hoje, não há, ainda, indicações precisas, mas sabemos que serão necessários mais espaços, um uso muito mais intenso dos espaços ao ar livre, mais recursos humanos. Haverá tudo isso? As educadoras e as professoras estarão disponíveis? A sua quantidade será suficiente? Tantas perguntas, poucas certezas.

Das primeiras experiências, emergem algumas indicações: é necessário trabalhar muito intensamente com as educadoras, as professoras, o pessoal de apoio; todos/as devem estar preparados/as, conhecer os protocolos de saúde e de segurança, ter a possibilidade de expressar todas as suas incertezas, todos os seus medos e encontrar uma forte coesão no grupo de trabalho, porque, posteriormente, deverão demonstrar tranquilidade aos pais e às mães e às crianças. Os pais e as mães devem estar envolvidos/as, é preciso explicar-Ihes o que será diferente, menos próximo, menos íntimo, mais difícil. Deveremos ter certeza de que poderemos trabalhar juntos, compartilhando as responsabilidades.

Muitos de nós já estão fazendo isso, mas nem todos, nem todas as professoras e as educadoras querem fazê-lo.

Mas a incerteza e o medo podem ser vencidos apenas se os reconhecemos e os respeitamos, e o pensamento voltado para as crianças, para os questionamentos e para as respostas que temos de encontrar conversando com elas são o desafio e o impulso para conseguirmos. Será necessário tempo, será um ano crucial, não para voltarmos a ser como antes, isso é impossível; talvez para sermos diferentes e melhores do que antes. 
Explicaremos às crianças que enfrentaremos as novas regras juntos: tentamos, é possível conseguir isso. Com as crianças maiores (4, 5, 6, anos), pode-se, também, brincar um pouco com o distanciamento, encontrar soluções novas, regras divertidas. Com as menores, é mais difícil. Temos de usar mais a voz como contato, encontrar atividades novas, acostumar as crianças ao fato de que, se o contato for mais próximo, os adultos usarão máscara ou a máscara com viseira... Estamos aprendendo e aprenderemos com as crianças também.

A formação comum, os espaços para se comunicar e expressar as dúvidas, as emoções e as dificuldades serão fundamentais.

Notamos que crianças menores, quando veem as educadoras a distância, ou as encontram novamente nos centros recreativos de verão, se emocionam, não precisam de muito tempo para se ambientar novamente: lembram-se, reconhecem, reencontram, quase imediatamente, o contato e prevalece a alegria pelo espaço reconquistado e pelo encontro com os outros.

As crianças maiores, a partir dos 4 anos, têm mais dificuldade: às vezes, dizem isto: "ficamos todos esses meses com a mamãe e o papai, é difícil"; precisam de mais tempo, Ihes desagradam os hábitos que mudaram - não se abraçarem, não poderem se servir sozinhas à mesa, não poderem trazer alguma coisa de casa, não encontrarem mais determinados materiais como os bichinhos de pelúcia.

Expressam dúvidas, medos, falam do vírus.

Essas primeiras observações, coletadas nos Centros recreativos de verão, confirmam os dados da pesquisa supracitada.

O que acontecerá? As educadoras, as professoras conseguirão superar a paralisia da incerteza, a comunicar uma razoável serenidade às crianças e aos pais e mães? Quais recursos podemos implementar?

Antes de tudo, trabalhar mais em grupo, renovar o senso de responsabilidade em relação a todas as crianças, sobretudo as mais frágeis, as mais vulneráveis. No mundo da infância, sentem-se muito essa consciência e a necessidade de transformar os numerosos encontros desses meses em verdadeiras redes de troca e de apoio recíproco entre profissionais da educação. Nem todos terão essa consciência, mas a maior parte das educadoras terá, mesmo depois de meses recebendo, tardiamente, apenas a "renda do INPS", mesmo com os seus salários excessivamente baixos. Mas teremos de trabalhar muito, juntos, e isso poderá favorecer o desenvolvimento do sistema integrado 0-6, que prevê maior continuidade tanto vertical quanto horizontal (entre diversos órgãos gestores, Estado, prefeituras, cooperativas). Teremos de 
trabalhar mais com os pais e as mães, e muitos de nós já o fizeram nesses meses, compreender as suas dificuldades, os medos, o trabalho que Ihes faltará. Teremos de ser rigorosas/os em conhecer e aplicar os protocolos de segurança, mas também teremos de ser flexíveis e criativas. Fazer muito mais com menos, porque chegarão recursos novos, mas não bastarão, porque a incerteza continuará, porque navegamos à deriva, mesmo que, neste momento, na Itália, não de modo perfeito, não suficientemente unidos; de qualquer forma, se está pensando nas crianças.

$\mathrm{E}$, se observarmos os meninos e as meninas, as crianças concretas, aquelas que mais precisam da creche e da escola, cada menino ou menina, encontraremos novas pistas para acrescentar à nossa experiência, procuraremos novos equilíbrios. As crianças nos ajudarão.

\title{
REFERÊNCIAS A DOCUMENTOS OFICIAIS DO GOVERNO
}

MIUR-Commissione Infanzia Sistema Integrato 0-6 (D.Igs 65/2017). Orientamenti Pedagogici sui LEAD-legami educativi a distanza: un modo diverso di fare nido e scuola dell'infanzia, abril, 2020.

ISS (Istituto Superiore di Sanità), COVID-19 n.43/2020, Indicazioni ad interim per un appropriato sostegno alla salute mentale dei minori di età durante la pandemia COVID-19. 2020.

\section{NOTAS}

DEPOIMENTO SOBRE O FECHAMENTO DAS CRECHES NA ITÁLIA: COMO RESISTIR À INCERTEZA EM TEMPOS DE PANDEMIA?

Testimonianza sulla chiusura dei nidi in Italia: come resistere all'incertezza in tempi di pandemia?

Testimony on the closure of ECEC in Italy: How to resist uncertainty in times of pandemic?

\section{Susanna Mantovani Professora emérita de Pedagogia geral e social Università degli Studi Milano Bicocca Milão, Itália susanna.mantovani@unimib.it (1) https://orcid.org/0000-0002-2608-7795}

\author{
Tradução: Daniela Aparecida Vieira \\ Doutora em Letras - Língua, Literatura e Cultura Italianas (USP) \\ Pós-doutorado em Linguística Aplicada e Estudos da Linguagem (PUC-SP) \\ Professora de português e de italiano \\ Centro Integrado de Educação de Jovens e Adultos (CIEJA) Perus I \\ São Paulo-SP, Brasil \\ daniela.apvieira@yahoo.com.br \\ http://orcid.org/0000-0002-1197-7429
}


Endereço de correspondência da principal autora

Università degli Studi Milano Bicocca. Milão, Itália.

Endereço profissional de correspondência da tradutora

Centro Integrado de Educação de Jovens e Adultos (CIEJA) Perus I. São Paulo, Brasil.

CONTRIBUIÇÃO DE AUTORIA

Concepção e elaboração do manuscrito: S. Mantovani

Coleta de dados: S. Mantovani

Análise de dados: S. Mantovani

Discussão dos resultados: S. Mantovani

Revisão técnica: Ana Lúcia Goulart de Faria

Tradução: Daniela Aparecida Vieira

\section{CONJUNTO DE DADOS DE PESQUISA}

O conjunto de dados que dá suporte aos resultados deste estudo não está disponível publicamente.

\section{FINANCIAMENTO}

Não se aplica.

\section{CONSENTIMENTO DE USO DE IMAGEM}

Não se aplica.

\section{APROVAÇÃO DE COMITÊ dE ÉTICA EM PESQUISA}

Não se aplica.

\section{CONFLITO DE INTERESSES}

Não se aplica.

LICENÇA DE USO - uso exclusivo da revista

Os autores cedem à Zero-a-Seis os direitos exclusivos de primeira publicação, com o trabalho simultaneamente licenciado sob a Licença Creative Commons Attribution (CC BY) 4.0 International. Esta licença permite que terceiros remixem, adaptem e criem a partir do trabalho publicado, atribuindo o devido crédito de autoria e publicação inicial neste periódico. Os autores têm autorização para assumir contratos adicionais separadamente, para distribuição não exclusiva da versão do trabalho publicada neste periódico (ex.: publicar em repositório institucional, em site pessoal, publicar uma tradução, ou como capítulo de livro), com reconhecimento de autoria e publicação inicial neste periódico.

PUBLISHER - uso exclusivo da revista

Universidade Federal de Santa Catarina. Núcleo de Estudos e Pesquisas da Educação na Pequena Infância - NUPEIN/CED/UFSC. Publicação no Portal de Periódicos UFSC. As ideias expressadas neste artigo são de responsabilidade de seus autores, não representando, necessariamente, a opinião dos editores ou da universidade.

EDITORES - uso exclusivo da revista Márcia Buss-Simão e Kátia Agostinho.

HISTÓRICO - uso exclusivo da revista

Recebido em: 10-12-2020 - Aprovado em: 10-12-2020 